\title{
DESARROLLO DE LA LITERATURA BOLIVIANA CONTEMPORÁNEA: ENTREVISTA A BLITHZ LOZADA PEREIRA EN JULIO DE 2021
}

\section{DEVELOPMENT OF CONTEMPORARY BOLIVIAN LITERATURE: INTERVIEW WITH BLITHZ LOZADA PEREIRA IN JULY 2021}

\author{
Jesús Miguel Delgado Del Aguila \\ Universidad Nacional Mayor de San Marcos, Perú \\ tarmangani2088@outlook.com
}

Recibido: 02 de septiembre de $2021 \quad$ Aceptado: 13 de octubre de 2021

Blithz Lozada Pereira nació en Oruro (Bolivia) en 1964. Es miembro de número de la Academia Boliviana de la Lengua desde el 2009, fecha en la que expuso su discurso "La educación del indio en el pensamiento filosófico de Franz Tamayo", con el que fue admitido. Es miembro honorario de la Asociación Peruana de Educación Intercultural. Ha sido coordinador, director, consultor y organizador de investigaciones y eventos académicos e institucionales. Obtuvo la licenciatura en Filosofía, así como realizó estudios de posgrado en Ciencias Sociales, Educación Superior, Filosofía y Ciencias Políticas. Asimismo, se especializó en políticas, organización y gestión de la ciencia, la tecnología y la innovación. Se ha desempeñado como docente. En la actualidad, enseña en la Universidad Mayor de San Andrés en La Paz. En su mayoría, sus investigaciones se enfocan en la problemática andina de la actualidad. Entre algunas de sus publicaciones, se encuentran las siguientes: Sugerencias intempestivas (1998), Educar para gobernar (2009), La educación del indio en el pensamiento filosófico de Franz Tamayo (2010), Theatrum ginecologicum (2012), La educación intercultural en Bolivia (2005), Cosmovisión, historia y política en los Andes (2007), Ciencia, tecnología e innovación en Bolivia: contexto internacional, investigación universitaria y prospectiva científica (2011), Políticas científicas, tecnológicas y de innovación en Bolivia (2016), Cultura política, ciencia y gestión de gobierno en América Latina (2017) y Políticas comparadas de conocimiento y bienestar en seis países sudamericanos (2018).

Simón Bolívar fue quien logró constituir a Bolivia como República, además de conseguir su independencia. Frente a ello, ¿usted considera que en la actualidad este suceso histórico repercute en la producción literaria del país? 
Yo personalmente creo que el impacto ha sido mínimo sobre la Literatura en Bolivia. Sin embargo, asumo que quien conoce el tema a fondo, habiendo realizado una bibliografía sobre Simón Bolívar, es el actual director interino de la Academia Boliviana de la Lengua: don José Roberto Arze.

Un factor medular de la historia latinoamericana es su vínculo con el pasado colonial y, sobre todo, la cosmovisión que se tiene del sujeto andino. Este ha sido llevado a la Literatura de varios países como si se tratase de un personaje que se resiste a la modernización y que ha adoptado una condición de barbarie. Frente a ese ideal, ¿cómo ha ido cambiando esa percepción en los estudios literarios de Bolivia?

Si por "estudios literarios" usted se refiere a la crítica literaria, las modas mundiales recientes influyen en Bolivia, como en todas partes, en la valoración de lo indígena. Es decir, existe una sobrevaloración. Entretanto, si usted se refiere a la producción literaria en sí misma, por ejemplo, el tema indígena ha tenido una valoración significativa desde inicios del siglo XX. Eso ha ocurrido con Alcides Arguedas. Y, en lo que concierne a la producción intelectual amplia y diversa, incluida la poesía, se corrobora con el caso de Franz Tamayo. Al respecto, se encuentra uno de mis libros titulado Cosmovisión, historia y política en los Andes (2006).

¿Cómo se aprecia la intervención de la Academia Boliviana de la Lengua para preservar la Literatura y el lenguaje del país?

Las tareas de la Academia Boliviana de la Lengua en lo concerniente al conocimiento del español que se habla en el país y respecto de los estudios de la injerencia lingüística de las lenguas nativas, sobre todo el quechua y el aimara, son permanentes. En los distintos Boletines de la Academia que se publican regularmente desde hace décadas, y en especial en la revista Anuario de la corporación, se divulgan los estudios al respecto. Lamentablemente, no todo este material está actualmente en línea, aunque existe el propósito de difundirlo a través de los medios electrónicos.

Las publicaciones en revistas indexadas, así como la abundante información que existe en internet, han logrado destruir el obstáculo de no poder documentarse para emprender un buen estudio académico. Eso ha favorecido a muchos estudiantes a 
nivel mundial. Ante esa nueva realidad, ¿cómo cree que ha mejorado la investigación en el caso boliviano?

Quien quiere investigar actualmente dispone de los recursos, los medios y una amplia diversidad de facilidades para hacerlo, especialmente a través de internet. Sin embargo, existen también los intermediarios que administran la producción intelectual y científica. Una cultura abierta no debería incluir su intermediación. Los productores de conocimiento deberían poner a disposición del mundo entero, instantánea y gratuitamente, su obra sin costo alguno. Así no habría robo ni comercialización de ideas, censura ideológica o de diversos grupos corporativos, ni primacía de criterios de carácter extraacadémico en evaluaciones sesgadas. La propaganda no sería el recurso para validar ideas ni productos intelectuales, literarios o culturales.

\section{¿Considera que en un futuro próximo la investigación académica digitalizada logrará superar en lectura y audiencia a los estudios de soporte impreso?}

Presumo que sí y creo que debería ser así, puesto que el costo medioambiental de la publicación física de los libros es muy alto y en el futuro será mayor todavía. Además, los medios digitales realmente democratizan el acceso a la producción intelectual, cultural y científica. Las redes sociales deberían ocuparse más de motivar la lectura y no deberían existir murallas ni costo para los destinatarios de toda publicación. Una sociedad sin mediatización comercial ni injerencia de cualquier laya debería llegar a todo ciudadano del mundo, sin pagos extra que ni siquiera benefician a los autores ni escritores.

\section{REFERENCIAS}

Asociación de Academias de la Lengua Española. "Blithz Lozada Pereira", 2021, https://www.asale.org/academicos/blithz-lozada-pereira. Consultado el 1 de septiembre de 2021. 